\title{
Stereo- and Regioselective Halogenation of Norbornenes Directed by Neighboring Group Participation
}

\author{
Radoslav Z. Pavlović ${ }^{\mathrm{a}}$, Sarah E. Border ${ }^{\mathrm{a}}$, Judith Gallucci ${ }^{\mathrm{a}}$ and Jovica D. Badjić $\mathrm{a}^{\mathrm{*}}$ \\ ${ }^{a}$ Department of Chemistry and Biochemistry, The Ohio State University, 100 West 18th Avenue, Columbus, OH 43210 (USA)
}

\section{ARTICLE INFO}

\section{ABSTRACT}

\section{Article history:}

Received

Received in revised form

Accepted

Available online

Keywords:

Electrophilic Addition

Neighboring Group Participation

Bromination

Norbornenes

Haloalkane Synthesis

\begin{abstract}
Directing the outcome of electrophilic addition reactions of norbornenes could be a challenging task. We have found that the ionic addition of bromine to dichloro-norbornene $\mathbf{2}$ is accompained with the formation of a bromonium cation followed by anchimeric assistance of juxtaposed chlorine to give five-membered chloronium cation, which upon reacting with bromide gives norbornane 4 in $>90 \%$ yield. At higher temperatures, however, the radical addition of $\mathrm{Br}_{2}$ dominates so that dibromo compound $\mathbf{3}$ appears as the principal reaction product (72\%). Stereoand regioselective rearrangements of norbornenes, reported herein, could be of interest for the syntheses of complex haloalkanes.
\end{abstract}

2009 Elsevier Ltd. All rights reserved.
Molecular baskets of type $\mathbf{1}$ (Figure 1A) are dynamic modular hosts comprising a set of folded aromatic gates at their portal for controlling the rate by which small molecules enter/exit their inner cavity. ${ }^{1}$ These $C_{3}$ symmetric cavitands can be functionalized with polar groups to give amphiphiles ${ }^{2}$ or bolaamphiphiles $^{3}$ capable of assembling into hierarchical materials in aqueous environments. ${ }^{4}$ Moreover, baskets with amino acids at their portal have also been shown to (a) hold transition metal-containing ligands acting as a secondary coordination sphere in catalysis or sensing ${ }^{5}$ or (b) trap organophosphonates akin in size and shape to nerve agents. ${ }^{6}$ The preparation of the concave platform of these versatile hosts (Figure 1A), comprising a flat aromatic base fused to three bicyclo[2.2.1] heptane rings, ${ }^{7}$ begins with the bromination of norbornene compound $\mathbf{2}$ to give $\mathbf{3}$ in $72 \%$ yield (Figure $1 \mathrm{~B}$ ). ${ }^{8} \mathrm{At}$ a high temperature $\left(150^{\circ} \mathrm{C}\right)$, this reaction was suggested ${ }^{8}$ to occur via a radical mechanism ${ }^{9}$ with the principle product 3 forming by syn addition of bromine to the sterically more accessible exo side. At lower temperatures, ${ }^{8}$ however, we were unable to identify our desired product and refrained from fully characterizing the reaction's outcome by focusing on completing the synthesis of basket $\mathbf{1}$ (Figure 1). Accordingly, ionic halogenations of norbornene derivatives ${ }^{10}$ are known to be followed with Wagner-Meerwein rearrangements ${ }^{11}$ in which a complex mixture of products is obtained by way of $\sigma$-bridging nonclassical carbocations. ${ }^{12}$ In line with it, we re-examined the bromination of norbornenes of type 2 (Figure 1B) to discover an interesting rearrangement reaction taking place by anchimeric assistance of halogens. ${ }^{13}$ The rearrangement dominates the reaction's outcome at lower temperatures and can be directed to give one haloalkane product in a stereo- and regioselective manner. We reason that our discovery could be of interest for the rapid and stereoselective synthesis of complex haloalkanes acting as insecticides, fire retardants or pharmaceuticals. ${ }^{14}$

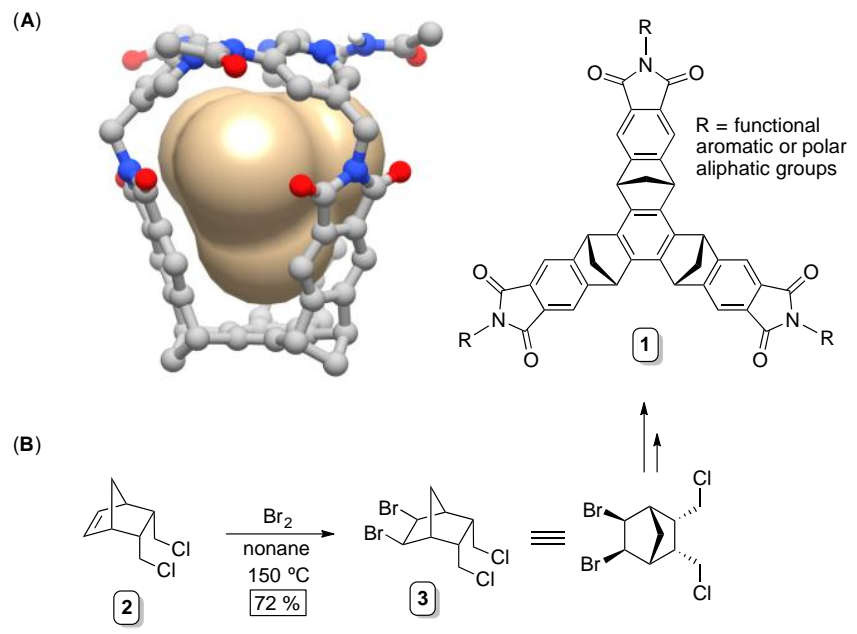

Figure 1. (A) Energy-minimized structure of a molecular basket (MMFFs, Spartan) holding $\mathrm{CBr}_{4}$ with folded aromatic gates at its portal. Chemical structure of basket $\mathbf{1}$ is shown on the right. (B) Bromination of $\mathbf{2}$ at a high temperature was reported to give $\mathbf{3}$ as the major product.

A gradual addition of bromine to compound $\mathbf{2}$ in dichloromethane was found to, within a range of temperatures (from -78 to $150{ }^{\circ} \mathrm{C}$, Table 1), lead to the formation of two products $\mathbf{3}$ and $\mathbf{4}$ in different proportions (Scheme 1A). To quantify the outcome of these reactions, we used GC and NMR while the constitutional and stereoisomeric assignment of products was completed with 2D NMR spectroscopy. 
Table 1. The bromination of $\mathbf{2}$ at various temperatures and in different solvents gives two products $\mathbf{3}$ and $\mathbf{4}$, whose ratio was determined with gas chromatography.

\begin{tabular}{lccc}
\hline \multicolumn{1}{c}{ Solvent } & Reaction Conditions ${ }^{\mathrm{a}}$ & Compound $\mathbf{3}(\%)$ & Compound $\mathbf{4}(\%)$ \\
\hline $\mathrm{CH}_{2} \mathrm{Cl}_{2}$ & $-78^{\circ} \mathrm{C}$ & $4^{\mathrm{b}}$ & $93^{\mathrm{b}}$ \\
$\mathrm{CH}_{2} \mathrm{Cl}_{2}$ & $-78{ }^{\circ} \mathrm{C} ; 1$ mol equiv. of $2,4,6$-tri-tert-butylphenol & 2 & 98 \\
$\mathrm{CH}_{2} \mathrm{Cl}_{2}$ & $25^{\circ} \mathrm{C}$ & $9^{\mathrm{b}}$ & $86^{\mathrm{b}}$ \\
$\mathrm{CH}_{2} \mathrm{Cl}_{2}$ & $25{ }^{\circ} \mathrm{C} ; 1$ mol equiv. of $2,4,6$-tri-tert-butylphenol & 3 & 97 \\
$\mathrm{C}_{9} \mathrm{H}_{20}$ & $150^{\circ} \mathrm{C}$ & 72 & 28 \\
$\mathrm{C}_{9} \mathrm{H}_{20}$ & $150^{\circ} \mathrm{C} ; 3.1$ mol equiv. of 2,4,6-tri-tert-butylphenol & 37 & 63 \\
\hline
\end{tabular}

${ }^{a}$ One molar equivalent of $\mathrm{Br}_{2}$ was used in all reactions. ${ }^{\mathrm{b}}$ Non-reacted substrate 2 comprises the remaining material.

In accordance with the assignment, $E_{2}$ eliminations of $\mathbf{3}$ and $\mathbf{4}$ promoted with strong base $t$-BuOK gave olefins $\mathbf{9}$ and $\mathbf{1 0}$ (Scheme 1B) with the expected exo removal of halides dominating each reaction's outcome; note that $\mathbf{3}$ gives $\mathbf{9}$, while $\mathbf{4}$ leads to compound 10. At last, the conversion of $\mathbf{2}$ into $\mathbf{3}$ and $\mathbf{4}$ (Scheme 1A) is a kinetically controlled process. After products $\mathbf{3}$ and 4 were kept in nonane at $150{ }^{\circ} \mathrm{C}$ for 15 minutes, we found $\left({ }^{1} \mathrm{H}\right.$ NMR $)$ that their proportion $(3: 4=59: 41)$ remained unchanged.

To account for the predominant formation of $\mathbf{4}$, at lower temperatures (Table 1), we reasoned that an ionic addition of bromine to 2 should yield bromonium cation ${ }^{15} \mathbf{5}$ in equilibrium with nonclassical cation $7 .{ }^{10}$ Next, a rapid conversion of threemembered bromonium 5 into the more stable five-membered chloronium $6(\Delta E>10)^{16}$ is expected to take place (Scheme 1A). ${ }^{17}$ At last, the chloronium 6 could react with juxtaposed bromide nucleophile at its less hindered carbon along $\mathrm{C}-\mathrm{Cl}^{+}$bonds (pathway a) to give the principle product 4. Alternatively, the substitution at the more hindered C- 2 could take place to give product 3 (pathway b, Scheme 1A). In this vein, one may also surmise that the formation of $\mathbf{3}$ could occur by the exo attack of the bromide on the electrophilic C-2 in 7 although this reaction is known to be a less preferred mode of the opening (higher $\left.E_{\mathrm{a}}\right)^{10}$ of norbornyl cation. In fact, a complete absence of the 1,3substitution product $\mathbf{8}$, among others (Scheme 1 ),${ }^{10}$ is indicative of the nonclassical ion 7 not participating in the reaction. To further account for the formation of cis dibromide $\mathbf{3}$, we noted

(A)

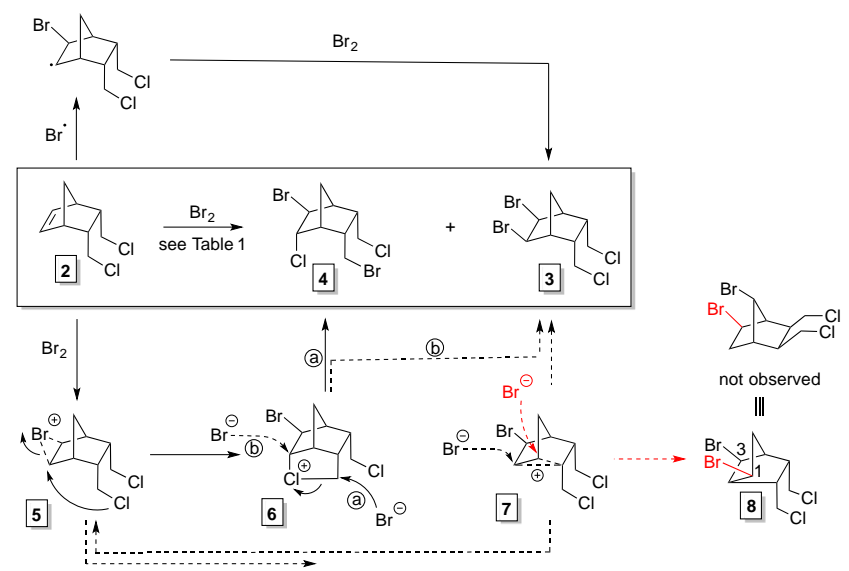

(B)

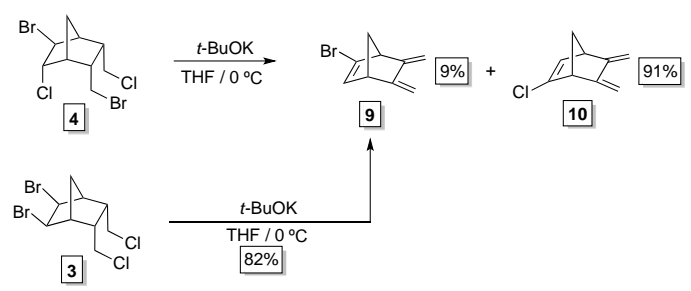

Scheme 1. (A) Postulated mechanistic pathways for the bromination of norbornene derivative 2. (B) Elimination reactions of $\mathbf{3}$ and $\mathbf{4}$ gave the expected alkenes $\mathbf{9}$ and $\mathbf{1 0}$. that greater thermal energy supplied to the reacting system (i.e. heating) would promote the formation of this molecule (Table 1). On the basis of earlier studies, ${ }^{9,11}$ we reasoned that higher temperatures ought to facilitate the homolytic cleavage of bromine thereby promoting a radical bromination occurring via radical intermediate (Scheme 1A). Indeed, the addition of radical quencher (2,4,6-tri-tert-butylphenol) to the reaction mixture suppressed the production of $\mathbf{3}$ (Table 1) to validate its formation via radical pathway! The results of this experiment also suggest that the aforementioned contribution of the ionic pathway $b$ (Scheme 1A) is playing a minor role (if any) in giving cis dibromide 3. To summarize, the bromination of $\mathbf{2}$ occurs by simultaneous ionic and radical pathways: the first dominates at lower temperatures and is mediated by halogen anchimeric assistance, while the later prevails at higher temperatures via syn addition of bromine.

The results of the bromination of bis-mesylate $\mathbf{1 1}$ and thioether 15 (Figure 2) give credence to the notion that the elusive and five-membered chloronium ion ${ }^{16-17} \mathbf{6}$ (Scheme 1A)

(A)

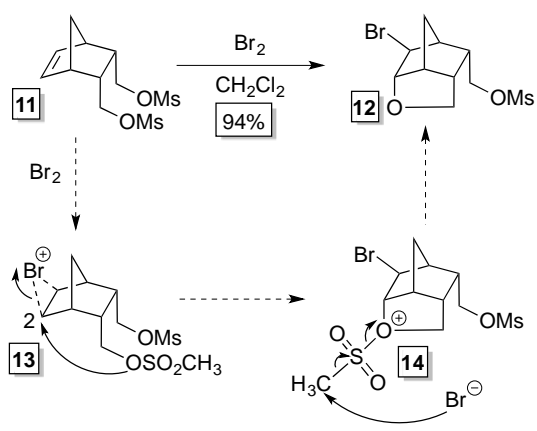

(B)

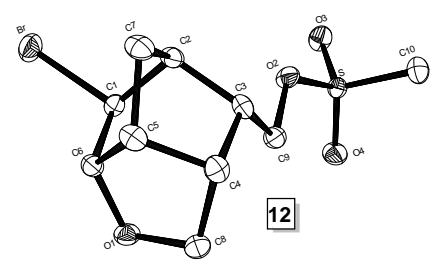

(C)

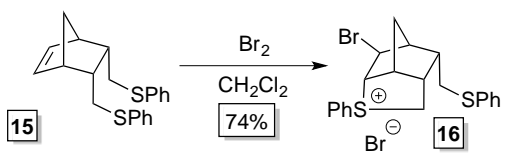

Figure 2. (A) The bromination of bis-mesylate $\mathbf{1 1}$ results in 5-exotrig cyclization of $\mathbf{1 3}$ giving cyclic ether 12. (B) ORTEP representation of the structure of $\mathbf{1 2}$ in solid state; single crystals of 12 were obtained by slow evaporation of its $\mathrm{CH}_{2} \mathrm{Cl}_{2} /$ hexane solution. (C) The bromination of $\mathbf{1 5}$ gives sulfonium salt $\mathbf{1 6}$.

takes part in the ionic addition described above. That is to say, when bromine was added to $\mathbf{1 1}$ there followed an exclusive formation of cyclic ether $\mathbf{1 2}$ in $94 \%$ yield (Figure 2A). We deduce that a rapid nucleophilic attack of an oxygen atom from methylsulfonate group in bromonium 13 on juxtaposed C-2 carbon gives intermediate $14 .^{18}$ The attack of bromide anion on the polarized and unhindered methyl group then prompts a rapid departure of good leaving groups $\left(\mathrm{SO}_{2}\right.$ and cyclic ether) and 
therefore the formation of 12; the nucleophilic attack of the bromide at the sulfur atom is another possibility for the conversion of $\mathbf{1 4}$ into 12. Importantly, the solid-state structure of cyclic ether 12 corroborates the spectroscopically deduced trans relationship of the bromide and ether oxygen groups; in fact, stereoselective syntheses of tetrahydrofurans ${ }^{18}$ and halogenolactons ${ }^{19}$ by 5-exo-trig cyclizations have already been reported and discussed by others. ${ }^{20}$ Finally, thioether 15 was in the same manner converted into cyclic sulfonium salt $\mathbf{1 6}$ (Figure 2C), which was stable enough for isolation and full characterization at ambient conditions.

To additionally examine the scope of the procedure, we studied the stereoselective bromination of dibromo- and dioiodo-
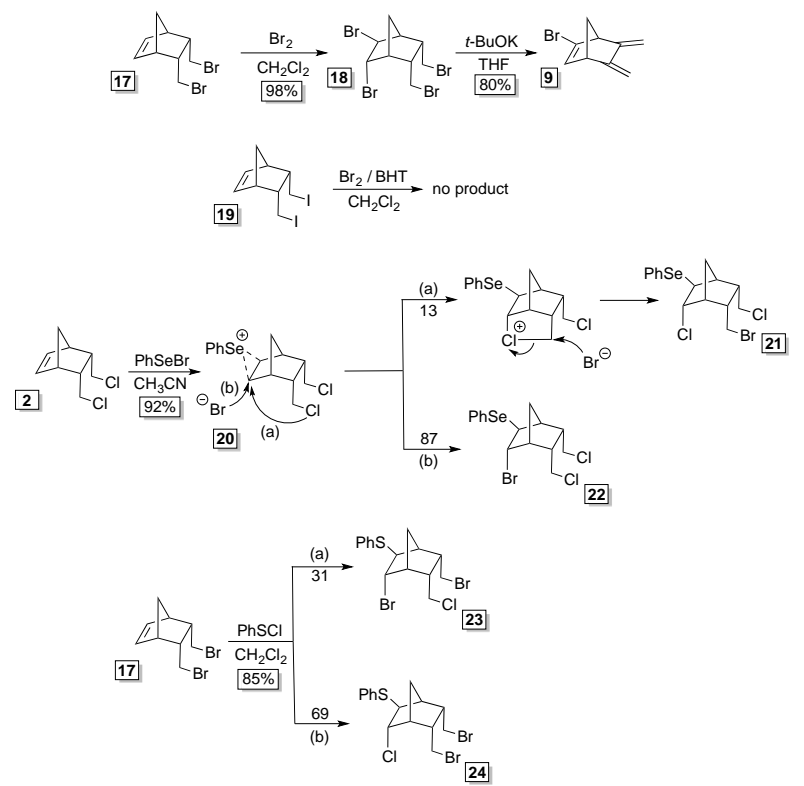

Scheme 2. The anchimeric assistance of either chlorine or bromine atoms affects the outcome of the examined electrophilic addition reactions in a predictable manner. The bromination of 19 at $-78{ }^{\circ} \mathrm{C}$ with 3,5-di-tert-4-butylhydroxytoluene (BHT, 3 mol equiv.) did not show any product ( ${ }^{1} \mathrm{H}$ NMR spectroscopy).

\section{Acknowledgments}

This work was financially supported with funds obtained from the U.S. National Science Foundation under CHE-1305179. We would like to thank S. Jing and Prof. T. V. RajanBabu of the Ohio State University for assistance with gas chromatography.

\section{References and notes}

(1) (a) Hermann, K.; Ruan, Y.; Hardin, A. M.; Hadad, C. M.; Badjic, J. D. Chem. Soc. Rev. 2015, 44, 500; (b) Rieth, S.; Hermann, K.; Wang, B.-Y.; Badjic, J. D. Chem. Soc. Rev. 2011, 40, 1609; (c) Pratumyot, Y.; Chen, S.; Hu, L.; Polen, S. M.; Hadad, C. M.; Badjic, J. D. Org. Lett. 2016, 18, 4238. (2) Ruan, Y.; Chen, S.; Brown, J. D.; Hadad, C. M.; Badjic, J. D. Org. Lett. 2015, 17, 852 .

(3) Chen, S.; Polen, S. M.; Wang, L.; Yamasaki, M.; Hadad, C. M.; Badjic, J. D. J. Am. Chem. Soc. 2016, 138, 11312.

(4) Chen, S.; Ruan, Y.; Brown, J. D.; Hadad, C. M.; Badjic, J. D. J. Am. Chem. Soc. 2014, 136, 17337.

(5) Zhiquan, L.; Polen, S.; Hadad, C. M.; RajanBabu, T. V.; Badjic, J. D. J. Am. Chem. Soc. 2016, 138, 8253.

(6) (a) Ruan, Y.; Dalkilic, E.; Peterson, P. W.; Pandit, A.; Dastan, A.; Brown, J. D.; Polen, S. M.; Hadad, C. M.; Badjic, J. D. Chem. Eur. J. 2014, 20, 4251; (b) Ruan, Y.; Taha, H. A.; Yoder, R. J.; Maslak, V.; Hadad, C. M.; Badjic, J. D. J. Phys. Chem. B 2013, 117, 3240.

(7) (a) Zonta, C.; Cossu, S.; De Lucchi, O. Eur. J. Org. Chem. 2000, 1965; (b) Reza, A. F. G. M.; Higashibayashi, S.; Sakurai, H. Chem. Asian J. 2009, norbornenes 17 and 19 (Scheme 2). With more nucleophilic halogens $(\mathrm{I}>\mathrm{Br}>\mathrm{Cl}),{ }^{21}$ embedded in the bicyclic reactants, we expected a more effective anchimeric assistance along the series $\mathbf{2} \rightarrow \mathbf{1 7} \rightarrow \mathbf{1 9} .{ }^{16}$ Indeed, in the case of $\mathbf{1 7}$ there was a sole formation of tetrabromo product $\mathbf{1 8}$ without any competing radical bromination at $-78{ }^{\circ} \mathrm{C}$ (Scheme 2); note that compound 18 was found to be unstable at $150{ }^{\circ} \mathrm{C}$ in nonane $(15 \mathrm{~min})$, and possibly giving elimination products that were difficult to distinguish with ${ }^{1} \mathrm{H}$ NMR spectroscopy. Interestingly, compound 19 would in the presence of bromine give a complex mixture of products yet upon the addition of radical quencher BHT there was no reaction observed. Currently, we have no additional experimental data to provide an explanation for this observation. With phenylselenyl bromide, the electrophilic selenylation of $\mathbf{2}$ in $\mathrm{CH}_{2} \mathrm{Cl}_{2}$ gave rise to two products 21 and 22 with, presumably, both arising from common seleniranium ion 20 (Scheme 2). ${ }^{22}$ In particular, we postulate that $\mathbf{2 1}$ forms by the anchimeric assistance of the adjacent chlorine atom (pathway a, Scheme 2) setting the trans stereochemistry at carbons C-2 and C-3 of the norbornane and allowing the positional exchange of two different halogen atoms. We also hypothesize that in consequence of a greater persistency of seleniranium ion $\mathbf{2 0}$ (Scheme 2), than bromonium 5 (Scheme $1 \mathrm{~A}){ }^{23}$ the classical anti electrophilic addition $\left(\mathrm{Ad}_{\mathrm{E}} 2\right)$ of $\mathrm{PhSeBr}$ took place with the dominant formation of 22; the ratio of 21:22 was determined with ${ }^{1} \mathrm{H}$ NMR spectroscopy to be 13:87 (Scheme 2 ). That is to say, the more stable and bridged cationic intermediate $\mathbf{2 0}$ is sufficiently persistent to allow the nucleophilic attack by not only neighboring $\mathrm{CH}_{2} \mathrm{Cl}$ group but also the external bromide anion. At last, the electrophilic sulfenylation ${ }^{24}$ of $\mathbf{1 7}$ with phenylsulfenyl chloride gave the expected products $\mathbf{2 3}$ and $\mathbf{2 4}$ by mechanism akin to the electrophilic selenylation. ${ }^{25}$

In conclusion, we discovered a synthetic method for obtaining polyhalogenated derivatives of norbornane via anchimeric assistance of halogens. The procedure is straightforward, high yielding, regio- and stereoselective with potential to be extended to a variety of bicyclic or cyclic systems and thereby facilitating the synthesis of natural products and other useful materials. ${ }^{14,26}$

4, 1329; (c) Bolzan, A.; Bortoluzzi, M.; Borsato, G.; Fabbro, C.; Dastan, A.; De Lucchi, O.; Fabris, F. Helv. Chim. Acta 2015, 98, 1067.

(8) Maslak, V.; Yan, Z.; Xia, S.; Gallucci, J.; Hadad, C. M.; Badjic, J. D. J. Am. Chem. Soc. 2006, 128, 5887.

(9) Tutar, A.; Taskesenligil, Y.; Cakmak, O.; Abbasoglu, R.; Balci, M. J. Org. Chem. 1996, 61, 8297.

(10) Marshall, D. R.; Reynolds-Warnhoff, P.; Warnhoff, E. W.; Robinson, J. R. Can. J. Chem. 1971, 49, 885.

(11) Gueltekin, D. D.; Taskesenligil, Y.; Dastan, A.; Balci, M. Tetrahedron 2008, 64, 4377 .

(12) Scholz, F.; Himmel, D.; Heinemann, F. W.; Schleyer, P. v. R.; Meyer, K.; Krossing, I. Science 2013, 341, 62.

(13) Capon, B. Quart. Rev. 1964, 18, 45

(14) (a) Chung, W.-j.; Vanderwal, C. D. Angew. Chem., Int. Ed. 2016, 55, 4396; (b) Xia, W. J.; Li, D. R.; Shi, L.; Tu, Y. Q. Tetrahedron Lett. 2002, 43, 627.

(15) Brown, R. S. Acc. Chem. Res. 1997, 30, 131.

(16) Shellhamer, D. F.; Davenport, K. J.; Forberg, H. K.; Herrick, M. P.; Jones, R. N.; Rodriguez, S. J.; Sanabria, S.; Trager, N. N.; Weiss, R. J.; Heasley, V. L.; Boatz, J. A. J. Org. Chem. 2008, 73, 4532.

(17) Peterson, P. E. Accounts Chem. Res. 1971, 4, 407

(18) Rychnovsky, S. D.; Bartlett, P. A. J. Am. Chem. Soc. 1981, 103, 3963.

(19) Srebnik, M.; Mechoulam, R. J. Chem. Soc., Chem. Commun. 1984, 1070 .

(20) (a) Bedford, S. B.; Bell, K. E.; Bennett, F.; Hayes, C. J.; Knight, D. W.; Shaw, D. E. J. Chem. Soc., Perkin Trans. 1 1999, 2143; (b) Barks, J. M.; Weingarten, G. G.; Knight, D. W. Perkin 1 2000, 3469; (c) Knight, D. W. Prog. Heterocycl. Chem. 2002, 14, 19; (d) Nichols, C. J. Synth. Commun. 2003, 33, 2167; (e) Ranganathan, S.; Muraleedharan, K. M.; Vaish, N. K.; Jayaraman, N. Tetrahedron 2004, 60, 5273.

(21) Winstein, S.; Grunwald, E. J. Am. Chem. Soc. 1948, 70, 828.

(22) Garratt, D. G.; Kabo, A. Can. J. Chem. 1980, 58, 1030.

(23) Carey, F. A.; Sundberg, R. J.; Editors Advanced Organic Chemistry, Part A: Structure and Mechanisms, Fifth Edition, 2007.

(24) (a) Zefirov, N. S.; Sadovaya, N. K.; Novgorodtseva, L. A.; Bodrikov, I. V. Tetrahedron 1978, 34, 1373; (b) Peluso, P.; Greco, C.; De Lucchi, O.; Cossu, S. Eur. J. Org. Chem. 2002, 4024. 


\section{Tetrahedron}

(25) Raasch, M. S. J. Org. Chem. 1975, 40, 161

(26) (a) Nilewski, C.; Geisser, R. W.; Ebert, M.-O.; Carreira, E. M. J. Am.

Chem. Soc. 2009, 131, 15866; (b) Sohn, T.-i.; Kim, D.; Paton, R. S. Chem. -

Eur. J. 2015, 21, 15988. 


\section{Graphical Abstract}

Stereo- and Regioselective Halogenation of

Leave this area blank for abstract info.

Norbornenes Directed by Neighboring

Group Participation

Radoslav Z. Pavlovića ${ }^{\text {, Sarah E. Border }}{ }^{\mathrm{a}}$, Judith Gallucci ${ }^{\mathrm{a}}$ and Jovica D. Badjić a $^{{ }^{*}}$

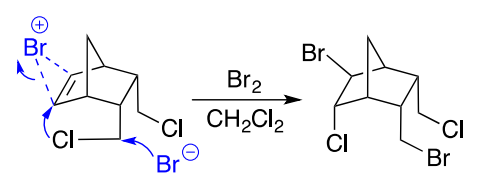

